\title{
Rapid Economic Development May Contribute Little to Healthcare in China Data analysis and indications of healthcare resources' availability and
distribution in China
}

\author{
Yifei Chen ${ }^{1}$ \\ ${ }^{1}$ Concord College, the United Kingdom, Zhejiang, China
}

\begin{abstract}
In the past several decades, China has experienced huge economic development. However, whether healthcare, as a crucial factor of social welfare, has also been improved is arguable. This essay conducts data analysis to assess the relationship between economic development and healthcare from two sides, whether the available healthcare resources have been expanded and whether the distribution of healthcare has been more reasonable, supported by results from data analysis process (regression) and size of Gini coefficient based on population and geographical area respectively.
\end{abstract}

\section{INTRODUCTION}

The recent pandemic, the Covid-19, raises wide concerns about healthcare sectors. Different countries in various development stages and healthcare conditions all suffer from the pandemic [1]. Contrary to many people's expectation, developed countries like the United States failed to control the pandemic trend in time, while China, as a developing country that has not been equipped with as advanced healthcare as its developed counterparts, has achieved an impressive result. This arouses my interest in China's healthcare

The relationship between GDP growth and healthcare has been suggested that within less developed economies, the influence of GDP growth on healthcare is more important, while the reverse tends to be more significant in developed countries [2]. It is true that the past several decades has witnessed significant GDP growth in China, but whether healthcare has also been improved greatly thus benefitting social welfare remains debatable. Therefore, it is particularly worthwhile to investigate the relationship between GDP growth and healthcare.

\section{Methodology}

Data of available healthcare resources, including total number, the number by administrative divisions of healthcare institutions, medical personnel and healthcare beds and population size in each province, are collected from the China Hygiene and Health Statistical Yearbooks from 2017 to 2019, the geographical area was obtained from Wikipedia. The rates of GDP growth are found from the World Bank's Open Data.
To determine the relationship between GDP growth and increases in the volume of healthcare resources, data analysis process - regression in Excel is used. To measure regional disparity of the distribution of healthcare resources, the Lorenz Curve is constructed, according to which the Gini coefficient based on population and geographical area respectively is calculated. The entire process is also operated in Excel.

\section{Results}

The indicator of economic development in this essay is GDP growth, which is listed in Figure I. The available healthcare resources are divided into three categories: number of healthcare institutions, number of medical personnel and number of healthcare beds, which are shown in Table I.

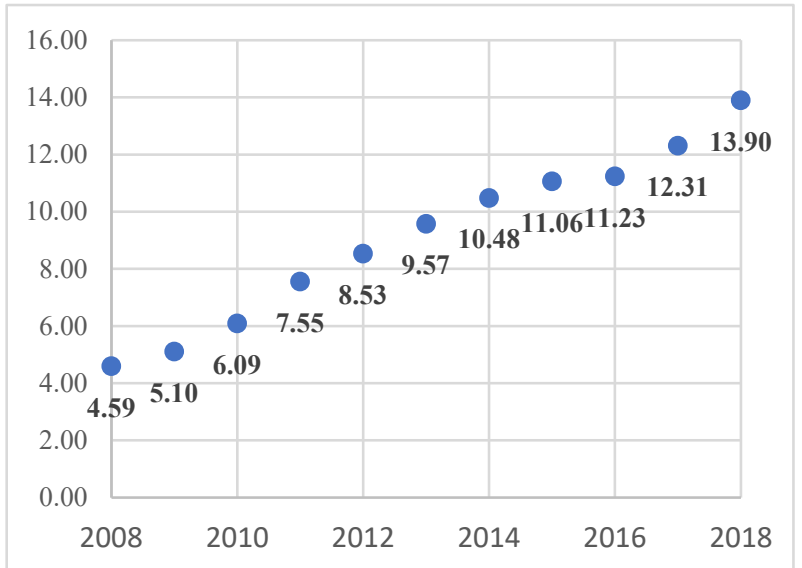

Figure 1. China's GDP in trillion (2020 US Dollar) [3]

$\overline{\text { yifeichen609@gmail.com }}$ 
TABLE I. Available HealthCare Resources in THOUSANDS [4]

\begin{tabular}{|c|c|c|c|}
\hline Year & $\begin{array}{c}\text { Healthcare } \\
\text { institutions }\end{array}$ & $\begin{array}{c}\text { Medical } \\
\text { personnel }\end{array}$ & $\begin{array}{c}\text { Healthcare } \\
\text { beds }\end{array}$ \\
\hline $\mathbf{2 0 0 8}$ & 891.48 & 5174.478 & 4038.7 \\
\hline $\mathbf{2 0 0 9}$ & 916.571 & 5535.124 & 4416.6 \\
\hline $\mathbf{2 0 1 0}$ & 936.927 & 5876.158 & 4786.8 \\
\hline $\mathbf{2 0 1 1}$ & 954.389 & 6202.858 & 5159.9 \\
\hline $\mathbf{2 0 1 2}$ & 950.297 & 6675.549 & 5724.8 \\
\hline $\mathbf{2 0 1 3}$ & 974.398 & 7210.578 & 6181.9 \\
\hline $\mathbf{2 0 1 4}$ & 981.432 & 7589.79 & 6601.2 \\
\hline $\mathbf{2 0 1 5}$ & 983.528 & 8007.537 & 7015.2 \\
\hline $\mathbf{2 0 1 6}$ & 983.394 & 8454.403 & 7410.5 \\
\hline $\mathbf{2 0 1 7}$ & 986.649 & 8988.23 & 7940.3 \\
\hline $\mathbf{2 0 1 8}$ & 997.433 & 9529.179 & 8404.1 \\
\hline
\end{tabular}

From the regression analysis shown in Table II, the factor that shows the highest $\mathrm{R}$ square is Changes in the number of healthcare institutions which is also the factor that has a p-value less than 0.05 . The coefficient is 0.576 , which suggests a positive correlation with GDP growth. However, changes in medical personnel and healthcare beds do not seem to have a statistically significant correlation with GDP growth. This is understandable because these variables are also affected by other factors such as educational resources.

TABLE II. REGRESSION RESUlTS OF GDP GROWTH AND Available HealthCARE Resources

\begin{tabular}{|c|c|c|c|}
\hline $\begin{array}{c}\text { Regression of } \\
\text { GDP growth } \\
\text { and }\end{array}$ & $\begin{array}{c}\text { Changes in } \\
\text { healthcare } \\
\text { institutions }\end{array}$ & $\begin{array}{c}\text { Changes } \\
\text { in } \\
\text { medical } \\
\text { personnel }\end{array}$ & $\begin{array}{c}\text { Changes } \\
\text { in } \\
\text { healthcare } \\
\text { beds }\end{array}$ \\
\hline Multiple R & 0.6804 & 0.1198 & 0.5397 \\
\hline R Square & 0.463 & 0.0143 & 0.2912 \\
\hline $\begin{array}{c}\text { Adjusted R } \\
\text { Square }\end{array}$ & 0.3959 & -0.1089 & 0.2026 \\
\hline $\begin{array}{c}\text { Standard } \\
\text { Error }\end{array}$ & 0.0089 & 0.0099 & 0.0148 \\
\hline Significance F & 0.0304 & 0.7417 & 0.1074 \\
\hline Coefficient & 0.5763 & 0.083 & 0.6578 \\
\hline P-value & 0.0303 & 0.7417 & 0.1074 \\
\hline
\end{tabular}

To analyze the phenomenon in which the growth in medical resources does not match the growth in GDP, it should be taken into consideration that medical resources need capital investment which is provided by the government or the private sector. In the case of China, because of the economic and political structure, the government plays a central role in all areas. Therefore, annual data of government expenditure on healthcare are also collected, as shown in Table III.

TABLE III. ANNUAL GOVERNMENT EXPENDITURE ON HealthCare Per Capita And Annual Changes

\begin{tabular}{|c|c|c|}
\hline Year & $\begin{array}{c}\text { Domestic general } \\
\text { government healthcare } \\
\text { expenditure per capita, } \\
\text { PPP in current } \\
\text { international dollar [5] }\end{array}$ & $\begin{array}{c}\text { Changes in } \\
\text { government } \\
\text { expenditure on } \\
\text { healthcare per } \\
\text { capita }\end{array}$ \\
\hline
\end{tabular}

\begin{tabular}{|l|c|c|}
$\mathbf{2 0 0 8}$ & 130.002 & \\
\hline $\mathbf{2 0 0 9}$ & 176.397 & $36 \%$ \\
\hline $\mathbf{2 0 1 0}$ & 199.374 & $13 \%$ \\
\hline $\mathbf{2 0 1 1}$ & 235.605 & $18 \%$ \\
\hline $\mathbf{2 0 1 2}$ & 283.227 & $20 \%$ \\
\hline $\mathbf{2 0 1 3}$ & 327.866 & $16 \%$ \\
\hline $\mathbf{2 0 1 4}$ & 370.765 & $13 \%$ \\
\hline $\mathbf{2 0 1 5}$ & 424.611 & $15 \%$ \\
\hline $\mathbf{2 0 1 6}$ & 443.3 & $4 \%$ \\
\hline $\mathbf{2 0 1 7}$ & 476.688 & $8 \%$ \\
\hline
\end{tabular}

To investigate the relationship between GDP growth and Changes in government expenditure on healthcare per capita, regression analysis is operated, and the result is shown in Table IV. The correlation is also not very statistically significant with a high p-value of 0.174 , which suggests that spending on healthcare from the government is not really consistent with the growth of GDP. To be more specific, the growth of spending on healthcare seems to be consistently lower than the growth of GDP. This reflects the rapid GDP growth does not translate into spending in healthcare.

TABLE IV. REgRESSION OUtPuts BetweEN GDP GROWTH AND Changes IN GovernMENT EXPENDITURE ON HEALTHCARE PER CAPITA

\begin{tabular}{|c|c|}
\hline $\begin{array}{c}\text { Regression Results, PPP in current } \\
\text { international dollars }\end{array}$ \\
\hline Multiple R & 0.496290063 \\
\hline R Square & 0.246303826 \\
\hline Standard error & 0.082727136 \\
\hline Significance F & 0.174175137 \\
\hline Coefficient & 0.032490814 \\
\hline P-value & 0.174175137 \\
\hline
\end{tabular}

To assess whether economic development has positively impacted healthcare sector and thus raising social welfare, besides the exploration of whether total available healthcare resources have been expanded, whether the existing problem of healthcare in China, inequality of resource distribution has been improved is also a key indicator. Hence, data on the regional distribution of healthcare resources are collected.

To measure the regional disparity, the results of the Gini coefficient based on population and geographical area from 2016 to 2018 are calculated from corresponding Lorenz curves as shown in Table V and Table VI. The Gini coefficient based on population size ranged between 0.070 and 0.187 , which indicates that healthcare resources tend to be equally distributed among the whole population. In contrast, geographically, the Gini coefficient ranged from 0.614 to 0.659 , which indicates large geographical disparity of healthcare resources.

TABLE V. The Gini COEFFICIENT OF HeAlthCARE RESOURCE DISTRIBUTION BASED ON POPULATION

\begin{tabular}{|c|c|c|c|}
\hline & $\mathbf{2 0 1 6}$ & $\mathbf{2 0 1 7}$ & $\mathbf{2 0 1 8}$ \\
\hline $\begin{array}{c}\text { Healthcare } \\
\text { institutions }\end{array}$ & 0.187 & 0.185 & 0.183 \\
\hline Medical personnel & 0.074 & 0.07 & 0.069 \\
\hline Healthcare beds & 0.072 & 0.073 & 0.074 \\
\hline
\end{tabular}


TABLE VI. The Gini Coefficient Of HealthCare Resource Distribution Based On Geographical AREA

\begin{tabular}{|c|c|c|c|}
\hline & $\mathbf{2 0 1 6}$ & $\mathbf{2 0 1 7}$ & $\mathbf{2 0 1 8}$ \\
\hline $\begin{array}{c}\text { Healthcare } \\
\text { institutions }\end{array}$ & 0.614 & 0.615 & 0.617 \\
\hline Medical personnel & 0.656 & 0.657 & 0.659 \\
\hline Healthcare beds & 0.638 & 0.638 & 0.637 \\
\hline
\end{tabular}

Figure II and III respectively display changes of the Gini coefficient based on population and geographical area from 2016 to 2018 . From the graph, it can be observed that values of all three indicators based on population fell slight from 2016 to 2018, while the ones based on the geographical area does not show any improvements.

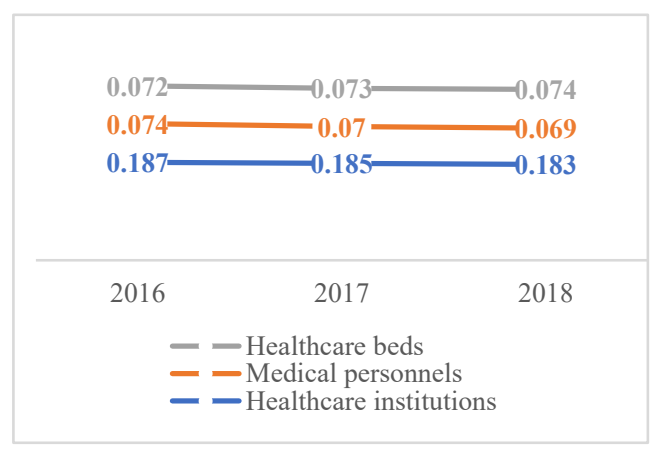

Figure 2. Changes of The Gini Coefficient of Healthcare Resources Distribution Based on Population of 2016-2018

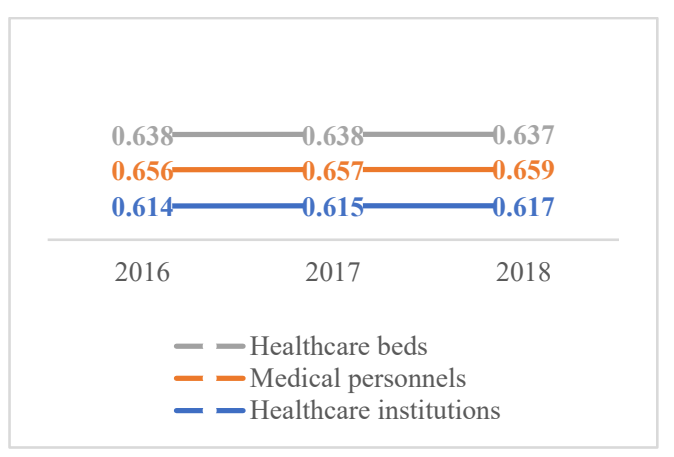

Figure 3. Changes of The Gini Coefficient of Healthcare Resource Distribution Based on Geographical Area in 20162018

\section{Discussion}

As indicated by the regression outputs between GDP growth and healthcare variables, rapid economic development in China actually did not enlarge the available healthcare resources correspondingly. Thus, it can be concluded that China has been more focused on economic growth than social welfare for the past few decades. The reason behind is complex, but government expenditure is deemed to be one of the major determinants, in consideration of the economic and political structure in China.

There are two main reasons why the government should make efforts to enhance healthcare. Firstly, from the perspective of humanitarianism, healthcare, as a birthright, should be guaranteed quality to everyone [6]. One important duty of the government is to protect citizen's rights [7], so besides focusing on economic growth, the government should also consider how to improve healthcare. Secondly, healthcare also brings great spillover effect. By ensuring one citizen's well-being, his or her social circle can also benefit, which is especially true in the pandemic period. Hence, the government should allocate sufficient resources to enhance healthcare thus raising social welfare.

However, it can be evaluated that weak correlation is due to long time lag instead of the lack of government spending. For example, the construction of healthcare institutions takes time, and the training process of highquality personnel also takes time. Therefore, the output of government expenditure on healthcare may not be immediately observed, and there might be a surge in the available healthcare resources in the future as a derived gain from the booming economy.

Another possible explanation is that impacts of other factors are mixed, which results in a less ambiguous outcome. For instance, education. The threshold of being a medical worker is strict, so it is the medical education coverage and standard that determine the number of medical personnel. Hence, without more sufficient support for medical education, the number of medical workers will not be pushed up significantly.

In addition, it could also be evaluated that the government focuses more on promoting the quality of healthcare resources. For example, purchase more highquality medical equipment, or set up more advanced medical wards. These changes cannot be reflected in the number of healthcare resources, but also improve the healthcare system in China and enhance social welfare.

Besides the issue over total available healthcare resources accessible within the economy, the regional disparity in China is also a serious problem. By observing the Gini coefficient values, a noticeable feature is that while the distribution of healthcare resources based on population is in low inequality, geographical distribution is extremely unequal. Furthermore, during the time interval from 2016 to 2018, the inequality over geographical districts is not alleviated at all, while the counterparts that based on population tend to be even more equally distributed.

This could be argued that the government aims to ensure access to healthcare for the whole population [8] rather than reach geographical equality. The population density in China is in extreme inequality, extremely high in the east and extremely low in the west [9]. If the goal is to reach geographically equal distribution of healthcare resources, it is not only unrealistic due to prohibitive costs but also an ineffective allocation of resources as a large proportion of healthcare resources will be idle. Moreover, considering the economic situation and living condition of the western and middle area [10], most people there cannot afford the costs of receiving comprehensive and professional treatments. Combining all the factors above, it is understandable that the government puts more emphasis on the equal distribution of healthcare resources based on population instead of geographical area.

However, the equal distribution of healthcare based merely on population may incur risks. For example, it may 
take a long time for people living far away from health institutions to receive treatment, and this is likely to influence their daily work and living schedule. Besides, when confronted with emergent pandemic issues such as Covid-19 or destruction incidents in some areas lacking healthcare resources, it also wastes precious time to transport patients and resources. Hence, geographical inequality exerts potential risks and it should be improved to some extent.

Some reasonable policies should be introduced or be widely adopted to improve the situation. For example, in some remote or rural areas, online consultation may be applied. Due to the inconvenience of transportation and possibly harsh living condition, well-educated medical personnel may not be willing to work there. Instead, telecommunication can share resource geographically without inducing huge costs and resource wastes [11]

\section{ConClusion}

Based on the data collected and analysis constructed, it can be concluded that in the past decade, despite great achievements in economic development with outstanding GDP performance, healthcare sector did not benefit correspondingly from the booming economy. Yet it could be evaluated that there might be a time lag to implement what the government has made efforts to, and some other factors like education may obscure the stimulating effect of GDP growth on healthcare. Or instead of raising the quantity of healthcare resources, the quality of healthcare in China is focused on more.

Besides the failure that the available healthcare resources were not enlarged correspondingly, the existing issue about extremely unequal geographical distribution of healthcare resources was not eased at all as observed from the Gini coefficient. It might not be in the government's goal to improve the geographical inequality, but considering the potential risks of extreme inequality, to some extents, the government should allocate more budgets or introduce some targeted policies to ameliorate the situation.

\section{ACKNOWLEDGMENT}

The author hopes to acknowledge and appreciate Williams Gao and Yufei Chen for support with methodology design and academic writing of this paper.

\section{REFERENCES}

1. T. Roosa, W. A. George, D. Ana, M. Elias, and W. D. Reginald, "The 2020 International Profiles of Health Care Systems: A Useful Resource for
Interpreting Country Responses to the COVID-19 Pandemic," Headquarters. 1 East $75^{\text {th }}$ Street. New York, NY 10021 Map, Commonwealth Fund, Jun. $10^{\text {th }}, 2020$, available at: https://www.commonwealthfund.org/blog/2020/202 0 -international-profiles-useful-resource-interpretingresponses-covid-19

2. B. E. David, K. Michael and P. Klaus, "Health and Economic Growth," 53113 Bonn, Germany, IZAInstitute of Labor Economics, Nov. 2018, available at: http://ftp.iza.org/dp11939.pdf

3. The World Bank, "GDP (current US\$) - China," 2019, available at:

https://data.worldbank.org/indicator/NY.GDP.MKT P.CD? end $=2019$ \&locations $=$ CN\&start $=1995$

4. www. Yearbookchina.com, "China Hygiene and Health Statistical Yearbook," 2019, https://www.yearbookchina.com/navibooklistn3019102807-1.html

5. The World Bank, "Domestic general government health expenditures per capita, PPP (current international \$) - China"

https://data.worldbank.org/indicator/SH.XPD.GHED .PP.CD?locations $=\mathrm{CN}$

6. Dr Tedros Adhanom Ghebreyesus, "Health is a fundamental human right," WHO statements, World Health Organization, Dec. $10^{\text {th }} 2017$, available at: https://www.who.int/mediacentre/news/statements/fu ndamental-human-right/en/

7. H. J. Steven, The First Duty of Government: Protection, Liberty and The Fourteenth Amendment, Duke Law Journal. Vol. 41:507, 1991, pp. 508-571.

8. Edited by B. Robert Lawton, L. G. Gordon, China's Healthcare System and Reform, Cambridge University Press, 2017, China's Healthcare Reform: Status and Outlook, Public Health Service: Objective 4. Page 145.

9. K. N. David, "China, People, Demographic trends, Population distribution," Encyclopedia Britannica, Aug $11^{\text {th }}, 2020$, available at: https://www.britannica.com/place/China

10. S. Maoying, "Poverty and Anti-poverty in China Mountain Region," available at: http://www.fao.org/3/XII/0510-A3.htm

11. S. Jeff, "Employing Mobile Devices to Improve Healthcare Communications and The Quality of Patient Care," Forbes, Feb. $3^{\text {rd }}$, 2020, available at: https://www.forbes.com/sites/forbescommunications council/2020/02/03/employing-mobile-devices-toimprove-healthcare-communications-and-thequality-of-patient-care/\#6ed76bf31a2f 